Health \& Medicine | Muniyandi \& Mohamed

\section{Direct cardiac reprogramming to regenerate the heart}

\begin{tabular}{|c|c|c|}
\hline $\begin{array}{l}\text { Infarction causes the loss } \\
\text { of a consequent number of } \\
\text { cardiac muscle cells. Unable } \\
\text { to self-regenerate, these cells } \\
\text { are replaced by fibroblasts. } \\
\text { This can lead to heart failure. } \\
\text { Priyadharshni Muniyandi, } \\
\text { doctoral researcher and Dr M. } \\
\text { Sheikh Mohamed, Associate } \\
\text { Professor at the Bio-Nano } \\
\text { Electronics Research Centre, } \\
\text { Toyo University, work on direct } \\
\text { cardiac reprogramming. Their } \\
\text { technique uses microRNA } \\
\text { encapsulated in a non-viral } \\
\text { nanocarrier: microRNA } \\
\text { targets cardiac fibroblasts and } \\
\text { genetically reprogrammes } \\
\text { them to cardiac muscle cells. } \\
\text { This constitutes a promising } \\
\text { therapeutic strategy that } \\
\text { could restore heart function } \\
\text { after cardiac injury. }\end{array}$ & $\begin{array}{l}\text { ardiac muscle cells, also called } \\
\text { cardiomyocytes, are essential } \\
\text { as they make up the heart } \\
\text { muscle responsible for pumping blood } \\
\text { throughout the body. Myocardial } \\
\text { infarction, better known as heart attack, } \\
\text { causes the loss of approximately } 25 \% \text { of } \\
\text { cardiomyocytes. These lost cells cannot } \\
\text { be self-regenerated. Instead, they } \\
\text { are replaced by another type of cells, } \\
\text { fibroblasts, that preserve structural } \\
\text { integrity by filling the void but that are } \\
\text { unable to assume the muscular function } \\
\text { of cardiomyocytes. This leads to heart } \\
\text { failure: the heart is unable to pump } \\
\text { blood efficiently enough to maintain a } \\
\text { blood flow that is sufficient to meet the } \\
\text { body's needs. }\end{array}$ & $\begin{array}{l}\text { been trying to target cardiac } \\
\text { fibroblasts and transform them } \\
\text { into cardiomyocyte-like cells. This } \\
\text { is a complex process that presents } \\
\text { numerous challenges. Researchers } \\
\text { at Toyo University's Graduate School } \\
\text { of Interdisciplinary New Science Ms } \\
\text { Priyadharshni Muniyandi and Dr M. } \\
\text { Sheikh Mohamed, have developed } \\
\text { a promising strategy that consists of } \\
\text { encapsulating microoNAA - a small } \\
\text { non-coding RNA molecule that can } \\
\text { genetically reprogramme a cell - in } \\
\text { biodegradable PLGA nanoparticles. } \\
\text { SAME DNA, DIFFERENT } \\
\text { SIGNALS, DIFFERENT CELLS } \\
\text { The body is made of different types } \\
\text { of cells that carry out different } \\
\text { functions. However, all cells have the } \\
\text { same genetic information: genes are } \\
\text { identical from one cell to another. What } \\
\text { differentiates cells of different types is } \\
\text { how these genes are expressed: within } \\
\text { the cell, the genetic code written in } \\
\text { DNA is translated into proteins but, } \\
\text { in each cell, not every single gene } \\
\text { is expressed. While some genes are } \\
\text { translated into proteins, others are } \\
\text { silenced. The combination of genes } \\
\text { that are expressed is modulated by } \\
\text { various signals. This is what gives a cell } \\
\text { its identity: cells end up with different } \\
\text { combinations of proteins that assume } \\
\text { specific functions. } \\
\text { Once its identity has been defined, } \\
\text { the cell keeps expressing the same } \\
\text { combination of genes that are } \\
\text { characteristic for its newly acquired } \\
\text { type. Like so, cardiomyocytes } \\
\text { express genes that are translated into } \\
\text { proteins giving the cells their unique }\end{array}$ \\
\hline
\end{tabular}

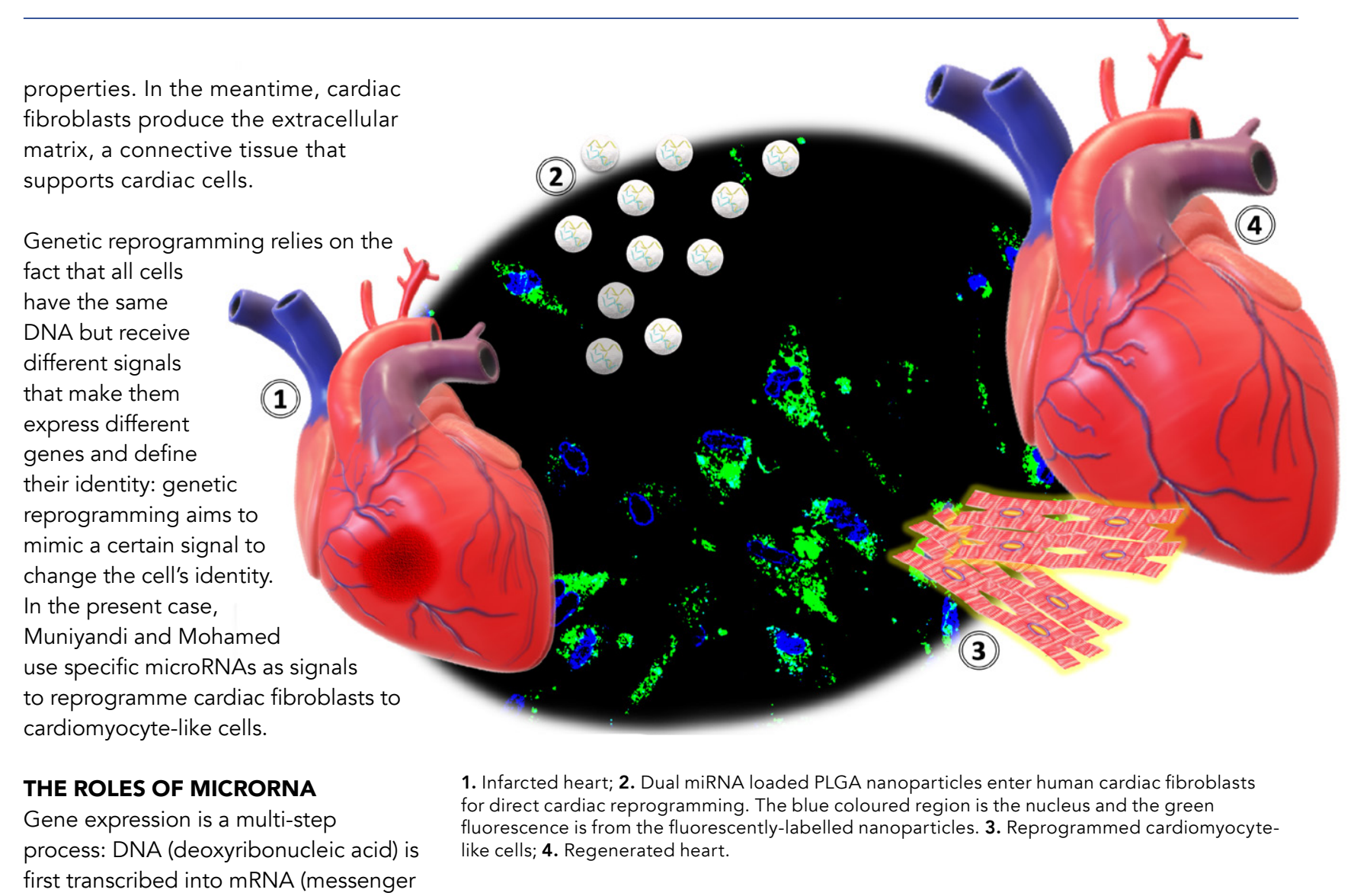

process: DNA (deoxyribonucleic acid) is first transcribed into mRNA (messenge ribonucleic acid) which is then translated into a protein. Transcription and translation are both modulated RNA molecules whose sequences are complementary to the sequences of target mRNAs, are part of these modulating factors: the binding of a microRNA to a target mRNA physically blocks protein translation.

By inhibiting protein translation of target mRNAs, microRNAs regulate protein production and, consequently, impact the various the targeted protein are involved. MicroRNAs have been associated, for example, with cell proliferation and differentiation. It is the case for miR-1 and miR-133a, two musclspecific microRNAs that are abundant in the heart and work together: miR133a enhances proliferation while miR-1 promotes differentiation of cardiac muscle cells.

The use of microRNA for direct cardiac reprogramming has been reported as a potential therapeutic

There is still no efficient therapy to restore heart function.

success was limited as the process is challenging: administering naked microRNA is difficult because it is easily degraded. Using miRaim to finding a carrier that can aim to finding a carrier that can cardiac fibroblasts.

CHOOSING THE RIGHT CARRIER Different types of carriers, or

Different types of carriers, or
vectors, have previously been

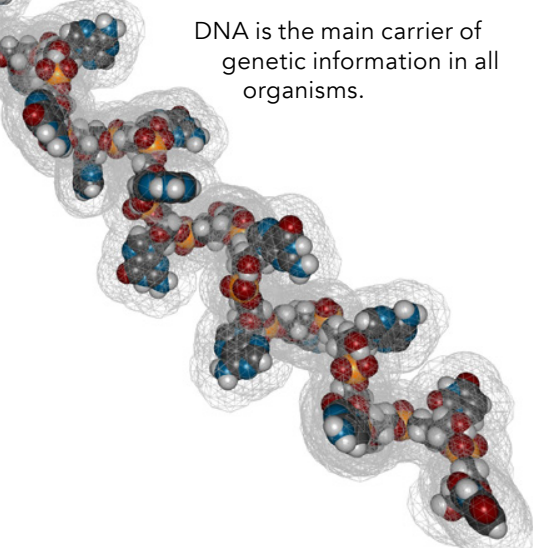

used to transfect target cells with genes of interest, but most of them are associated with adverse effects.

Viral vectors are convenient tools that rely on the system viruses use bility to introduce their the birity to introduce their genome into that are modified so that they are not pathogenic, and whose genetic material is replaced with the genes of interest. However, using a viral vector can lead to an alteration of gene expression, which is associated with many other side effects such as cancer.

Non-viral vectors such as Lipofectamin have also been used. Lipofectamine is a lipidic molecule that forms liposomes, vesicles which entrap the genes of interest and can easily merge with the target cell membrane. Though Lipofectamine containing microRNA cardiac fibroblasts, this system has limitations related, to their short has iflifif and transient gene expression. 
Polyethylenimine (PEI) is another nonviral vector. Positively-charged PE charged momplex wh negativelycell membrane The complex is then brought into the cell. Though PEI can prove to be an effective carrier, PEI-microRNA complexes are prone protein coronation: proteins cover the complexes, increasing their size by as much as ten times, which in turn can critically influence their uptake by cells and, therefore, reduce their transfection efficacy. To address this issue, the research team use biodegradable PLGA (Poly(lactic-co-glycolic acid)) nanoparticles to encapsul microRNA complexes.

SUCCESS OF THE NANOPARTICLES Muniyandi and Mohamed are first to report the use of microRNA delivery using PLGA nanoparticles as carrier for direct cardiac reprogramming of adult human cardiac fibroblasts (AHCFs) to cardiomyocyte-like cells. PEl is used to facilitate the encapsulation of miR-1 PLGA nanoparticles encapsulated with PEI-microRNA efficiently reprogrammed AHCFs to cardiomyocyte-like cells, the research team car
along the process.

The synthesis of PLGA-PEI-microRNA nanospheres was efficient, as around

encapsulated with PEI-microRNA.

To test the efficiency of PLGA nanospheres to transfect AHCFs Wh team also complexes and Lipofect of the potential adverse effects that can arise from transfection is cytotoxicity: because the vector is not an endogenous compound, there can be incompatibility issues leading to cellular stress and ultimately to cellu death. The cellular compatibility of PLGA nanospheres was confirmed as $80 \%$ of transfected cells were viable even with high concentrations of PLGA nanospheres. Cellular viability was better with PLGA nanospheres than with PEl-microRNA complexes or Lipofectamine. Besides evaluating cytotoxicity af the differentest the

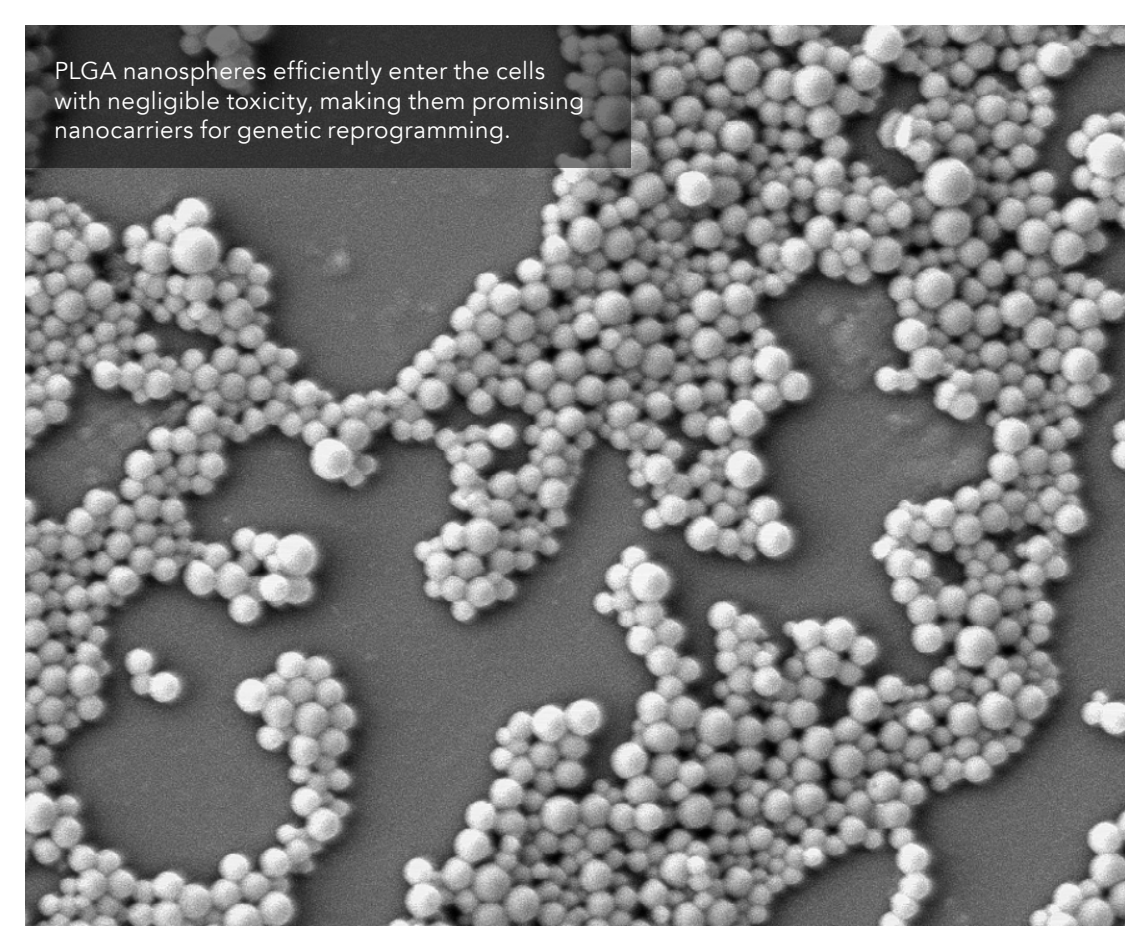

was to assess glutathione levels: a depletion of glutathione indicates cellular stress. In cells transfected with PLGA nanospheres, no reduction of GSH levels was observed while there was a slight depletion of GSH in cells transfected with Lipofectamine or PEImicroRNA complexes. These tests show that PLGA nanospheres are compatible with AHCFs and do not cause any significant damage.

PLGA nanospheres are able to efficiently enter the cells with negligible toxicity, which make the

creased greatly, and more than when AHCFs were transfected with PEImicroRNA complexes or Lipofectamine The researchers concluded that PLGA for direct cardiac reprogramming of fibroblasts to cardiac muscle cells.

\section{NANOFIBRES AND HOPE}

FOR THE FUTUR

There is one more step: PLGA nanoparticles are efficient vectors for genetic reprogramming in vitro but, to regenerate a heart, directly injecting microRNA is not the optimal stra

\section{PLGA nanoparticles are one of the ideal} choices for direct cardiac reprogramming of fibroblasts to cardiac muscle cells.

reprogramming. The next step was to check that, once the nanospheres were internalised in AHCFs, miR-1 and miR-133a efficiently reprogrammed the cells to cardiomyocyte-like cells. do this, the number of cells producing $\alpha$-actinin and CTnT (cardiac troponin was assessed. These two proteins are markers of cardiomyocytes. Therefore, the expression of these proteins confims that the cells have been reprogrammed to cardiomyocyte-like used, the number of cTnT-positive cells as the nanoparticles are short-lived and cardiac regeneration would therefore require several injections. To face this challenge, the Toyo University nanofibres which mimic extracellular priferation of the cardiac cells. The embed nanose of is project is to use these micropNA n nanofibres and nanofibre scaffolds for direct cardic reprogramming to rostiect hart function after cardiac injury. research team is now working on

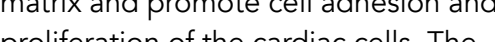

\section{Behind the Research Q 9 \\ Dr M. Sheikh Mohamed}

W: https://www.toyo. ac scip/en/research/labo-center/bnel//2@: W: https://www.toyo.ac.jp/en/academics/gs/glns/glns/

\section{Research Objectives}

The Bio-Nano Electronics Research Centre carries out advanced combined studies on bioscience and technology.

\section{Detail}

Bio-Nano Electronics Research Centre, Graduate School of Interdisciplinary New Science, Toyo University, 2100 Jupanan 350-8585

Bio

Priyadharshni Muniyandi is a final year Doctoral Scholar at the Graduate School of Interdisciplinary New Science, Toyo University, Japan, with the prestigious Japanese Governmen scholarship (MEXT). She has an M.Res Degree from the University of Glasgow, Hannover Medical University, Germany

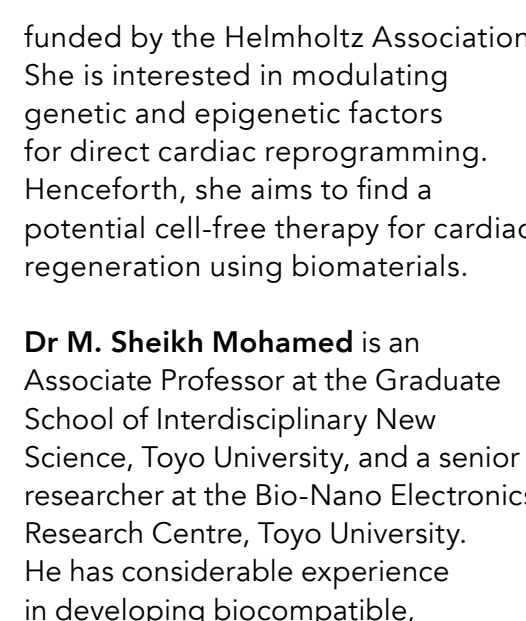

funded by the Helmholtz Association She is interested in modulating genetic and epigenetic factors for direct cardiac reprogrammin potential cell-free therapy for cardia regeneration using biomaterials.

Dr M. Sheikh Mohamed is an Associate Professor at the Graduate School of Interdisciplinary New Science, Toyo University, and a senior researcher at the Bio-Nano Electron Research Centre, Toyo University. in developing bible expatible,

multifunctional nanomaterials for biological applications with keen focus

\section{Funding}

Ministry of Education Culture, Sports Science and Technology (MEXT), Japan Toyo University, Japan

\section{Collaborators}

nandan Palaninathan

- DrTomofumi Ukai

- Prof Toru Mackawa

- Prof Tatsuro Hanajiri

\section{References}

Muniyandi P, et al. (2020). Poly(lactic-co-glycolic acid)/ Polyethylenimine Nanocarriers for Direct Genetic Reprogramming of MicroRNA Targeting Cardiac Fibroblasts. ACS Applied Nano Materials, [online] 3 (3), 2491-2505. https://doi.org/10.1021/acsanm. 9602586

Muniyandi P, et al. (2020). ECM Mimetic Electrospun Porous Poly (L-lactic acid) (PLLA) Scaffolds as Potential Substrates for Cardiac Tissue Engineering. Polymers, 12(2) (1)

Muniyandi P, et al. (2020). Direct Cardiac Reprogramming with Engineered miRNA Scaftolds. Curr Pharm Des, doi:10.

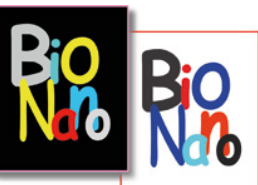

\section{Personal Response}

What is the biggest challenge that you overcame in

II Reprogramming adult human cells is much more complex due to their limited reprogramming capacity in believe of having accomplished this goal with a cocktail. of just two muscle-specific microRNAs. In comparison,
conventional reprogramming requires a cocktail of conventional reprogramming requires a cocktail of
different small molecules in numerous combinations, different small molecules in numerous combinations,
yet, the reprogramming efficiency is minimal. Therefore yet, the reprogramming efficiency
the present research provides a simpler and effective alternative for cardiac genetic reprogramming, which could in the future be translated to other defective-organ genetic reprogramming plattorms. In summary, more research on various permutations and combinations of microRNAs along with nanotechnology-based gene
delivery can help to reprogramme adult human cells to fully, functional cardiomyocytes through genetic reprogramming, paving the way for a solution towards the repair of a broken heart. 